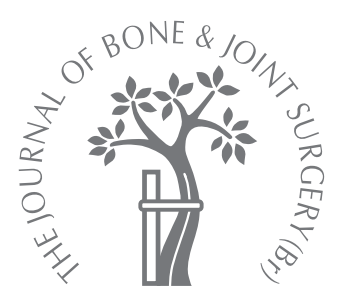

\title{
Proximal scaphoid rib graft arthroplasty
}

S. Veitch,

S. M. Blake, H. David

From Derriford Hospital, Plymouth, England
S. Veitch, MD, MRCS, Orthopaedic Specialist Registrar

Princess Elizabeth Orthopaedic Centre

Royal Devon and Exeter

Hospital, Barrack Road, Exeter EX2 5DW, UK.

as. M. Blake, BSc, MBBS, MRCS, Orthopaedic Specialist Registrar

Department of Orthopaedic Surgery

Torbay Hospital, Newton Road, Torquay, Devon TQ2 7AA, UK.

= H. David, FRCS, FRCS(Orth), Consultant Orthopaedic

Surgeon

Derriford Hospital, Derriford Road, Crownhill, Plymouth

PL6 8DH, UK.

Correspondence should be sent to Dr S. Veitch; e-mail: swveitch@doctors.org.uk

(C2007 British Editorial Society of Bone and Joint Surgery doi:10.1302/0301-620X.89B2. $18059 \$ 2.00$

$J$ Bone Joint Surg $[\mathrm{Br}]$ 2007:89-B:196-201.

Received 27 April 2006; Accepted after revision 17 October 2006

We prospectively reviewed 14 patients with deficiency of the proximal pole of the scaphoid who were treated by rib osteochondral replacement arthroplasty.

Improvement in wrist function occurred in all except one patient with enhanced grip strength, less pain and maintenance of wrist movement. In 13 patients wrist function was rated as good or excellent according to the modified wrist function score of Green and O'Brien. The mean pre-operative score of 54 (35 to 80 ) rose to 79 (50 to 90 ) at review at a mean of 64 months (27 to 103). Carpal alignment did not deteriorate in any patient and there were no cases of nonunion or significant complications.

This procedure can restore the mechanical integrity of the proximal pole of the scaphoid satisfactorily and maintain wrist movement while avoiding the potential complications of alternative replacement arthroplasty techniques and problems associated with vascularised grafts and salvage techniques.

Scaphoid fractures are common and the rate of union depends on many factors including the orientation of the fracture, its comminution and displacement. ${ }^{1-3}$ Fractures of the proximal pole, by virtue of the size of the fragments and often doubtful vascular viability, present a particular challenge. Several longitudinal studies have highlighted the risk of post-traumatic degenerative change in the presence of nonunion. ${ }^{4-6}$ The use of a compression screw with or without bone grafting has been successful in most instances. ${ }^{7,8}$ However, the treatment options are limited for those cases of persistent nonunion and a deficient proximal pole which are deemed to be unsuitable for conventional bone grafting techniques. A vascularised bone graft or some form of salvage technique which involves excision with or without an intercarpal fusion and various types of interposition graft have been described. ${ }^{9-18}$ Vascular grafting can be time-consuming, is technically demanding and may not improve the rate of union in patients with nonunion and an avascular proximal pole fragment. ${ }^{11}$ Salvage techniques such as excision of the scaphoid with either a medial column fusion or proximal row carpectomy can lead to improved relief from pain, but at the expense of loss of movement and grip strength and are typically reserved for those patients with associated degenerative changes within the wrist. ${ }^{12}$ The use of silastic as an interposition graft has fallen out of favour because of the risk of developing silicone synovitis. $^{13,14}$ Tendon grafts result in a loss of scaphoid height. ${ }^{15}$

The preliminary results for cadaver scaphoid allograft were good, ${ }^{16}$ but concern has been expressed regarding the risk of transmission of disease. More recently, pyrocarbon has been used as an interposition graft. ${ }^{17}$

The use of a rib graft is an established technique which was first described over 80 years ago. ${ }^{18}$ It has been used successfully for the treatment of injury to, and degeneration of, the temporomandibular joint. ${ }^{19}$ In orthopaedic surgery osteochondral grafts have been used in the treatment of injury to the proximal interphalangeal joint ${ }^{20}$ and degeneration of the first carpometacarpal joint. ${ }^{21}$ Sandow $^{22}$ described the use of a rib graft for the treatment of nonunion of the scaphoid in the presence of a relatively small proximal pole and in an avascular proximal pole. His preliminary results in 22 patients reviewed at a median follow-up of two years showed that there was functional improvement in all patients.

Since 1996 we have used an osteochondral rib graft replacement in selected patients with a deficient proximal pole or after failed surgery for proximal fractures of the scaphoid. We now present our results and compare them with the only series previously published. ${ }^{22}$ 

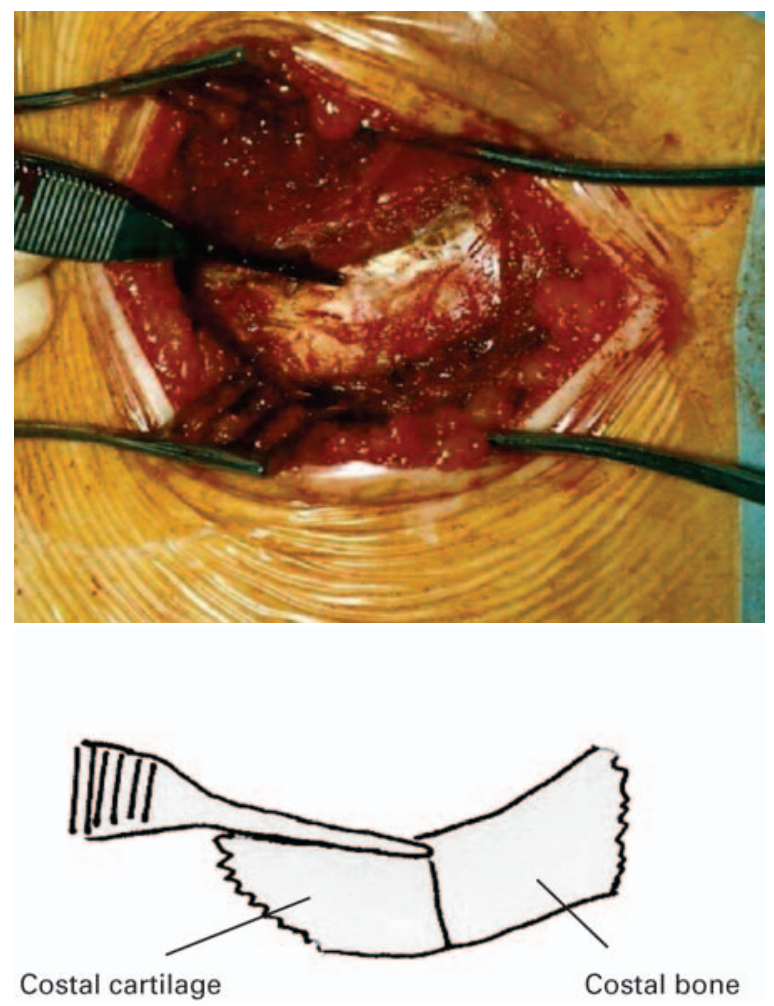

Fig. 1

Photograph and diagram of the left sixth rib before harvesting. The forcep points to the zone of transition between costal cartilage and bone. Approximately $5 \mathrm{~cm}$ of rib are harvested.

\section{Patients and Methods}

Between May 1996 and April 2002, 15 patients were treated by replacement of the proximal scaphoid using an osteochondral rib autograft. There were 14 men and one woman with a mean age at the time of surgery of 26 years (21 to 53). The indications for surgery included scaphoid nonunion with a proximal pole which was deemed to be unsuitable for conventional bone grafting because of its small size, fracture comminution or failed previous surgery. Patients with degenerative carpal change were excluded. Occasionally, this decision could only be made intraoperatively.

All patients had an established nonunion which had been diagnosed at least one year before surgery, and had persistent disabling symptoms. The mean time from the initial injury to surgery was six years (1 to 36 ). Six patients had previously undergone surgery, five with bone grafting with Herbert screw fixation ${ }^{7}$ and one by a Matte Russe procedure. $^{23}$ The mean time between the primary surgery and osteochondral grafting was 25 years (19 to 30 ).

Operative technique. A dorsal approach between the third and fourth extensor compartments was used. The mobile and/or comminuted proximal scaphoid fragment was excised retaining the dorsal scapholunate ligament whenever possible. A limited radial styloidectomy was performed if indicated and the distal scaphoid was resected back to healthy cancellous bone using a saw.

Through a transverse submammary incision a segment of the fifth or sixth rib $5 \mathrm{~cm}$ in length was harvested (Fig. 1). The graft was centred on the costochondral junction. Care was taken when separating the intercostal muscles from the rib to preserve the perichondral sleeve. The graft was shaped carefully with a scalpel and rongeurs to form a piece of bone $2 \mathrm{~mm}$ to $3 \mathrm{~mm}$ in size and with at least $5 \mathrm{~mm}$ of costal hyaline cartilage. We believe that this thin segment of retained bone facilitated union of the graft to the distal scaphoid. The graft was inserted into the scaphoid fossa with the bone abutting the prepared distal scaphoid and the chondral portion articulating with the distal radius. It was stabilised by two longitudinal Kirschner (K)-wires (Fig. 2). After trial reduction, further trimming of the graft was undertaken. The intention was to balance the need to preserve the length of the graft and thus the carpal height with the risk of overfilling the joint which in turn could compromise the resultant range of movement. The tip of each wire was bent slightly before being withdrawn deep to the chondral surface of the graft to allow compression. The dorsal wound was closed in layers over a subcutaneous suction drain, the tourniquet deflated and a backslab applied for the first five days followed by a forearm cast for six to eight weeks. The drain was removed at 24 hours and the patients discharged home on the day after surgery. The wires were removed under general anaesthesia at six to eight weeks, with immobilisation for a further two to four weeks.

Four standard scaphoid view radiographs were obtained pre-operatively and at regular intervals post-operatively. They were assessed for union of the graft, degenerative changes (assessed by loss of joint space and subchondral sclerosis in the radioscaphoid, scapholunate and lunocapitate joints), carpal height and carpal alignment. Carpal height was measured on a posteroanterior projection of the neutrally-positioned wrist using the carpal height ratio (carpal height divided by the length of the capitate; normal range $1.57 \pm 0.05) .{ }^{24}$ Carpal alignment was assessed by measuring the radiolunate and capitolunate angles on the lateral radiograph of the wrist. ${ }^{25}$

A functional assessment was undertaken pre-operatively and at the most recent follow-up using the modified wrist function score of Green and O'Brien (Table I). ${ }^{26}$ Grip strength was measured using a Jamar dynamometer (Lafayette Instruments, Lafayette, Indiana).

Statistical analysis. Initial and follow-up scores were compared using the Wilcoxon signed-rank test. A p-value $\leq 0.05$ was considered to be significant.

\section{Results}

We reviewed only those patients who had a minimum follow-up of two years.

One patient was lost to follow-up and was excluded. When last assessed, he had returned to his previous 


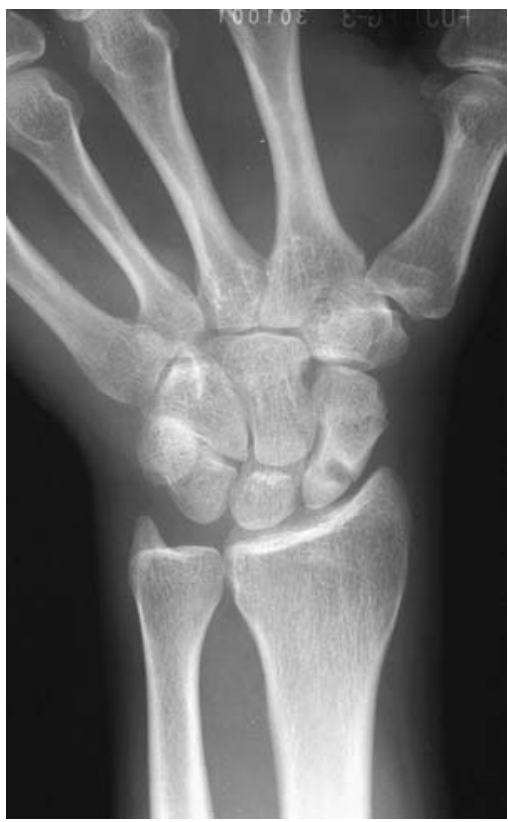

Fig. 2a

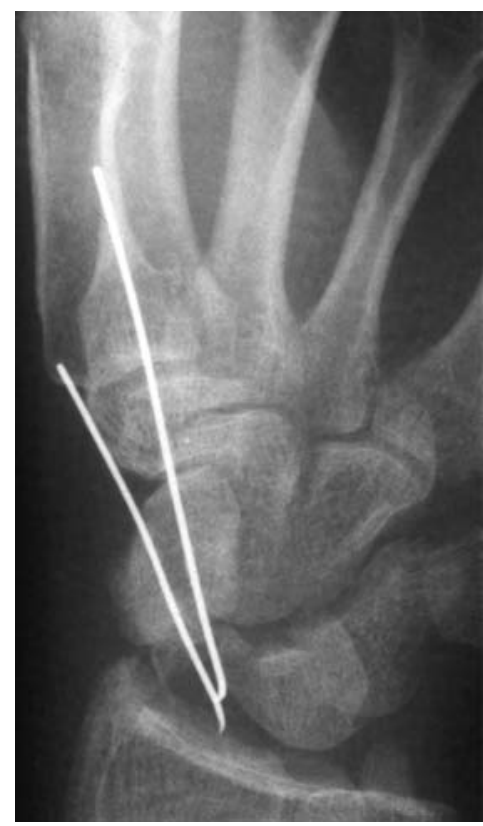

Fig. $2 b$

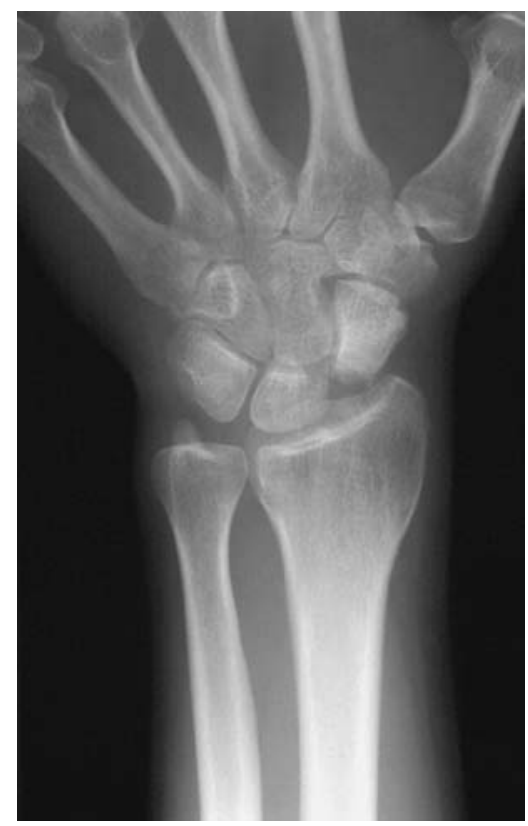

Fig. 2c

Figure 2a) pre-operative radiograph (posteroanterior view) showing nonunion at the proximal pole of the scaphoid, b) post-operative oblique view showing the rib graft fixed to the distal scaphoid using two parallel Kirschner wires and c) posteroanterior view at two years after surgery. The carpal height and scaphoid length are maintained.

Table I. The modified wrist function score of Green and $\mathrm{O}^{\prime} \mathrm{Brien}^{26}$

\begin{tabular}{|c|c|c|c|c|c|}
\hline Score & 0 & 10 & 15 & 20 & 25 \\
\hline Pain & Severe, pain at rest & $\begin{array}{l}\text { Moderate, activity } \\
\text { reduced, no pain at } \\
\text { rest }\end{array}$ & $\begin{array}{l}\text { Mild, regular, no } \\
\text { significant effect on } \\
\text { activity }\end{array}$ & Mild, occasional & No pain \\
\hline Range of movement (total arc; ${ }^{\circ}$ ) & $<40$ & 40 to 69 & 70 to 99 & 100 to 140 & $>140$ \\
\hline $\begin{array}{l}\text { Grip strength }(\%) \\
\text { (compared with other side) }\end{array}$ & $<50$ & - & 50 to 74 & 75 to 90 & Normal \\
\hline Activity & Unable to work & - & $\begin{array}{l}\text { Light duties due to } \\
\text { wrist pain }\end{array}$ & $\begin{array}{l}\text { Normal duties. } \\
\text { Some medication }\end{array}$ & $\begin{array}{l}\text { No } \\
\text { limitations }\end{array}$ \\
\hline
\end{tabular}

Table II. Functional outcome in the 14 patients

\begin{tabular}{|c|c|c|c|c|c|c|c|}
\hline \multirow[b]{2}{*}{ Case } & \multirow[b]{2}{*}{ Follow-up (mths) } & \multicolumn{2}{|c|}{ Grip strength/kg* } & \multicolumn{2}{|c|}{ Green and $\mathrm{O}^{\prime} \mathrm{Brien}^{26}$ score } & \multirow[b]{2}{*}{ Overall satisfaction } & \multirow{2}{*}{$\begin{array}{l}\text { Post-operative } \\
\text { employment }\end{array}$} \\
\hline & & Pre-operative & Post-operative & Pre-operative & Post-operative & & \\
\hline 1 & 56 & 31 & 24 & 65 & 75 & Good & Goldsmith \\
\hline 2 & 54 & 43 & 61 & 70 & 85 & Excellent & Builder \\
\hline 3 & 95 & 42 & 36 & 70 & 80 & Excellent & Engineer \\
\hline 4 & 31 & 32 & 56 & 40 & 85 & Good & Abattoir \\
\hline 5 & 96 & 30 & 56 & 65 & 75 & Excellent & Engineer \\
\hline 6 & 103 & 28 & 26 & 35 & 75 & Excellent & Builder \\
\hline 7 & 63 & 31 & 36 & 35 & 75 & Good & HGV driver \\
\hline 8 & 63 & 43 & 64 & 50 & 85 & Excellent & Carpenter \\
\hline 9 & 74 & 38 & 46 & 60 & 85 & Excellent & Car mechanic \\
\hline 10 & 49 & 32 & 36 & 80 & 85 & Excellent & Alarm fitter \\
\hline 11 & 70 & 36 & 36 & 50 & 50 & Fair & Computing \\
\hline 12 & 54 & 9 & 22 & 40 & 90 & Excellent & Factory work \\
\hline 13 & 27 & 44 & 48 & 45 & 80 & Excellent & Estate agent \\
\hline 14 & 64 & 24 & 38 & 45 & 80 & Good & Window fitter \\
\hline
\end{tabular}

employment without complications. There were 14 patients who were reviewed with a mean follow-up of 64 months (27 to 103) (Table II). The senior surgeon (HD) performed all aspects of each operation. The mean operating time was 1 hour and 40 minutes ( 1 hour 15 minutes to 2 hours). 


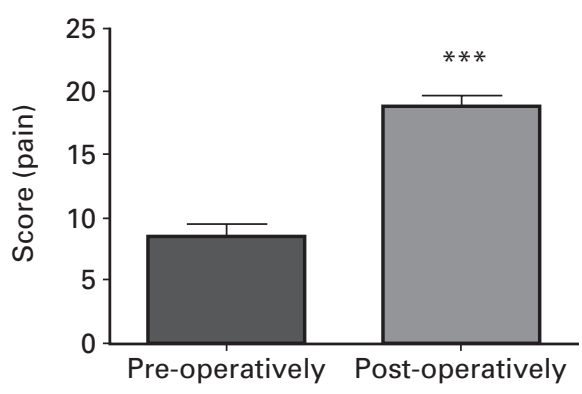

Fig. 3a

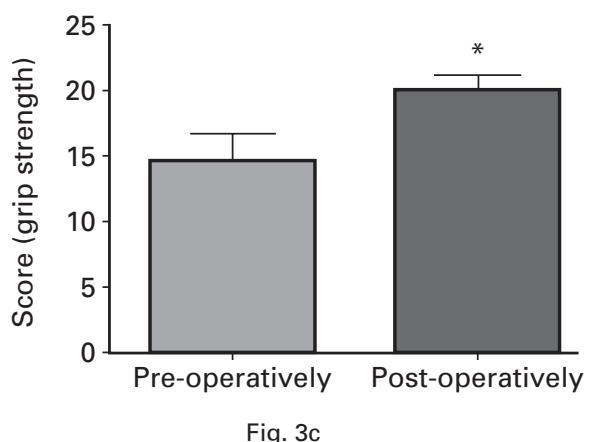

Bar charts showing pre- and post-operative scores for a) pain, b) range of movement, c) grip strength and d) activity. The cumulative score is the modified score of Green and $\mathrm{O}^{\prime}$ Brien $^{26}$ (Wilcoxon signed rank test, ${ }^{*} \mathrm{p}<0.05, * * * p<0.001$ )

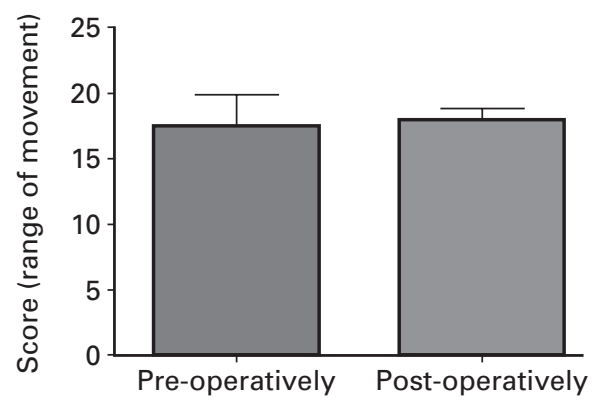

Fig. 3b

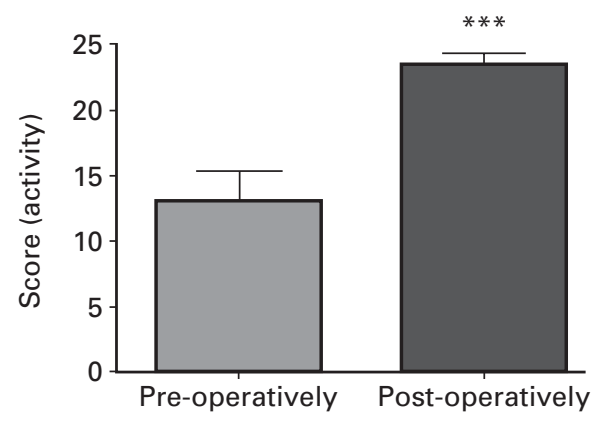

Fig. 3d
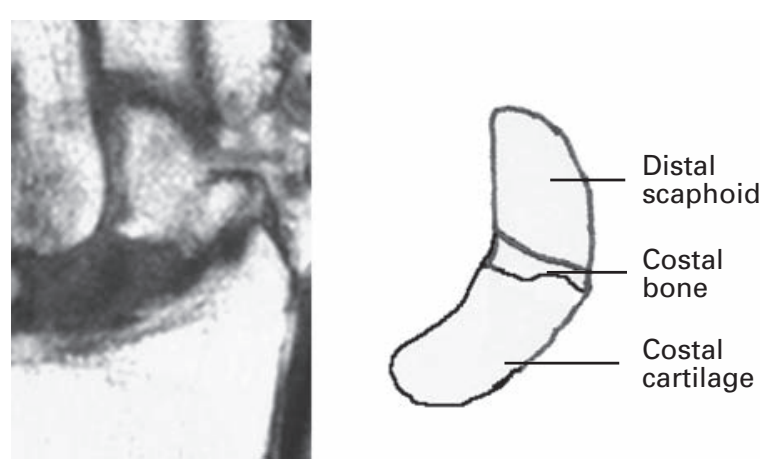

Fig. 4

MR scan and diagram of the scaphoid showing union of the dista scaphoid with the rib graft. The junction between the costal and chondral portions of the graft can be seen.

Two patients underwent further surgery to remove spurs arising from the dorsal radius in order to improve wrist extension. A K-wire broke in one patient and was left in situ without problems. There were no cases of pneumothorax or wound infection. No patient requested or is being considered for further surgery to the wrist.
The pre-operative score using the modified wrist functional assessment of Green and O'Brien ${ }^{26}$ improved from a mean of 54 (35 to 80$)$ to 79 (50 to 90$)$ ( $\mathrm{p}<0.001)$ at the most recent review. Grip strength improved from a mean of $33 \mathrm{~kg}$ (9 to 44) pre-operatively to $42 \mathrm{~kg}$ ( 22 to 64; $\mathrm{p}<0.05$ ) (Table II). Significant improvement was seen in pain and activity $(\mathrm{p}<0.001)$ and range of movement was maintained (Fig. 3).

The outcome was rated as good or excellent in 13 patients. All returned to their previous level of employment with a level of activity similar to that before the injury. One patient became the British amateur kickboxing champion five years after his surgery.

The only patient not rated as good or excellent was a Royal Marine commando. Although his recovery was such that he was able to deal with normal day-to-day activities it was not sufficient to allow him to cope with the rigours of life as a serviceman. He now works as a computer analyst.

Because of the radiolucent chondral and small bone components of the graft, the exact time to radiological union was difficult to determine. However, on the most recent scaphoid views there was no evidence of displacement of the graft in any patient. Proximal migration of the capitate between the scaphoid and lunate was not seen. A radio- 
lunate angle greater than $15^{\circ}$ and/or a capitolunate angle greater than $30^{\circ}$ were present in eight patients preoperatively and improved in all after surgery. There was no deterioration in carpal alignment in the remaining six patients. The carpal height ratio was reduced in eight patients pre-operatively and improved in three of these, remained the same in three and deteriorated in two. In one patient, degenerative changes were seen in the radioscaphoid and capitolunate joints six years after surgery. One other patient developed degenerative changes isolated to the radioscaphoid joint seven years after surgery. However, his original injury had been sustained ten years before surgery. There was no deterioration in the carpal height ratio in those patients in whom it had been normal before surgery.

\section{Discussion}

For most patients with an established nonunion of the scaphoid, iliac-crest bone grafting with internal fixation remains the treatment of choice. A vascularised graft is an uncommon but accepted option in those patients with an intact proximal pole. Alternative procedures involve either some form of intercarpal or total wrist fusion or excision of the proximal row of carpal bones. A vascularised graft is a technically demanding procedure and the alternative, salvage procedures, are not without their problems in terms of loss of movement and strength. The patient who presents with a small fracture of the proximal pole, especially when there is doubt with regard to viability, presents a particular dilemma. So too do those who have had failed previous surgery. Treatment options are limited in those with symptomatic proximal scaphoid deficiency and failed surgical treatment and we believe that the osteochondral portion of the rib used as an interposition graft in such patients provides structural support to the lateral column of the carpus, improving grip strength and functional activity while maintaining the range of movement.

The procedure has been described previously, but only with preliminary results. ${ }^{22}$ By using the wrist function score of Green and O'Brien ${ }^{26}$ we have been able to compare our results with this study. These results, at a mean of five years, are very similar to the results reported by $S$ andow ${ }^{22}$ at a mean of two years in terms of movement, strength and function. Thus, the technique is reproducible and the benefit to the patients after surgery is maintained into the medium term.

Two patients required debridement of bony spurs from the dorsal rim of the radius in order to improve their range of movement. We believe that these spurs develop as a result of elevating the joint capsule from the distal, dorsal radius. Since we modified the technique using a transverse capsulotomy, thereby leaving a small cuff of capsule attached to the distal radius for subsequent direct repair, we have not experienced any further cases of formation of a spur which has required removal.
The K-wires have a small bend at the tip (Fig. 2b) to allow compression at the site of the scaphoid graft. They are buried subcutaneously to minimise the risk of infection and are removed under general anaesthesia at six to eight weeks. We have had no difficulty in removing them, apart from in one patient in whom a wire had broken before removal and was left in situ without problems.

We considered that union had occurred when trabeculae were seen extending between the costal bone of the rib graft and the distal scaphoid. The assessment of radiological union can occasionally prove to be difficult and MRI may be useful (Fig. 4).

Inoue and Sakuma ${ }^{4}$ reported that osteoarthritis developed in $100 \%$ of patients with symptomatic scaphoid nonunion when the original fracture had been sustained at least ten years previously. Despite surgery, degenerative change developed in two patients in our series. Although no such change was identified either pre-operatively or at the time of surgery there was a gap of ten years between injury and surgery in one patient. Long-term follow-up of all our patients is planned in order to monitor the development of any radiological deterioration in carpal height, or alignment, or of frank degenerative change.

The scapholunate ligament is not secured to the interposed rib graft but is positioned in close proximity. This is similar to the technique for silastic replacement. We have not found any radiological evidence of migration of the capitate between the scaphoid and lunate suggestive of scapholunate dissociation and in the two patients who were re-explored the scapholunate ligament was firmly attached to the graft.

We cannot find any clinical or radiological reason why the patient who had previously been a Royal Marine Commando was not rated as highly as every other patient in our series, but the high physical demands of his work are worth noting.

We initially performed post-operative radiography of the chest in all patients on the day after surgery. Neither pneumothorax nor haemothorax was identified and we now no longer routinely request a post-operative chest radiograph. All patients in our series were discharged on the day after surgery.

An established scaphoid nonunion with a small proximal pole, especially of doubtful viability, and those cases in which previous surgery has failed, present a particular challenge. We believe that when feasible, the proximal scaphoid should be preserved and a bone graft with internal fixation used. A vascularised graft may be considered for those cases with an intact proximal pole in which a previous conventional graft has failed. In cases in which the vascularised graft has failed or more commonly in those patients with nonunion and collapse of the proximal pole or, alternatively, a small proximal pole which is considered to be unsuitable for bone grafting, we recommend a rib graft arthroplasty. The viability of such a graft with adaptive metaplasia of the articulating surface has been previously 
demonstrated on graft biopsy. ${ }^{22}$ Our results show that the technique is reproducible and the results sustainable at a mean follow-up of five years (2 to 8 ). All our patients returned to work with a functional outcome rated as good or excellent except one. We found the maintenance of movement particularly pleasing. Replacement of the proximal pole with an osteochondral graft diminishes activityrelated pain and maintains carpal alignment and range of movement in the wrist.

\section{Supplementary Material}

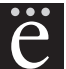

A supplementary table showing the pre-operative details of the 14 patients is available with the electronic version of this article on our website at www.jbjs.org.uk

No benefits in any form have been received or will be received from a commercial party related directly or indirectly to the subject of this article.

\section{References}

1. Barton NJ. The late consequences of scaphoid fractures. J Bone Joint Surg [Br] 2004;86-B:626-30

2. Leslie IJ, Dickson RA. The fracture carpal scaphoid: natural history and factors influencing outcome. J Bone Joint Surg [Br] 1981;63-B:225-30.

3. Ring D, Jupiter JB, Herndon JH. Acute fractures of the scaphoid. J Am Acad Orthop Surg 2000;8:225-31.

4. Inoue G, Sakuma M. The natural history of scaphoid nonunion: radiological and clinical analysis in 102 cases. Acta Orthop Trauma Surg 1996;115:1-4.

5. Duppe H, Johnell O, Lundborg G, Karlsson M, Redlund-Johnell I. Long-term results of fracture of the scaphoid: a follow-up study of more than thirty years. J Bone Joint Surg [Am] 1994;76-A:249-52.

6. Lindstrom G, Nystrom A. Natural history of scaphoid nonunion, with special reference to "asymptomatic" cases. J Hand Surg [Br] 1992;17:697-700.

7. Filan SL, Herbert TJ. Herbert screw fixation of scaphoid fractures. J Bone Joint Surg [Br] 1996; 78-B:519-29.

8. Daly K, Gill P, Magnussen PA, Simonis RB. Established nonunion of the scaphoid treated by volar wedge grafting and Herbert screw fixation. J Bone Joint Surg [Br] 1996;78-B:530-4.
9. Gabl M, Reinhart C, Lutz M, et al. Vascularized bone graft from the iliac crest for the treatment of nonunion of the proximal part of the scaphoid with an avascular fragment. J Bone Joint Surg [Am] 1999;81-A:1414-28.

10. Sawaizumi T, Nanno M, Nanbu A, Ito H. Vascularised bone graft from the base of the second metacarpal for refractory nonunion of the scaphoid. J Bone Joint Surg $[\mathrm{Br}]$ 2004;86-B:1007-12

11. Straw RG, Davis TR, Dias JJ. Scaphoid nonunion: treatment with a pedicled vascularized bone graft on the 1,2 intercompartmental supraretinacular branch of the radial artery. J Hand Surg [Br] 2002;27:413.

12. Cohen MS, Kozin SH. Degenerative arthritis of the wrist: proximal row carpectomy versus scaphoid excision and four-corner arthrodesis. J Hand Surg [Am] 2001;26:94104.

13. Carter PR, Benton LJ, Dysert PA. Silicone rubber carpal implants: a study of the incidence of late osseous complications. J Hand Surg [Am] 1986;11:639-44.

14. Haussman P. Long-term results after silicone prosthesis replacement of the proximal pole of the scaphoid bone in advanced scaphoid nonunion. J Hand Surg $[\mathrm{Br}]$ 2002;27:417-23.

15. Eaton RG, Akelman E, Eaton BH. Fascial implant arthroplasty for treatment of radioscaphoid degenerative disease. J Hand Surg [Am] 1989;14:766-74.

16. Carter PR, Malinin TI, Abbey PA, Sommerkamp G. The scaphoid allograft: a new operation for treatment of the very proximal scaphoid nonunion or for the necrotic, fragmented scaphoid proximal pole. J Hand Surg [Am] 1989;14:1-12.

17. Pequignot JP, Lussiez B, Allieu Y. An adaptive proximal scaphoid implant. Chir Main 2000;19:276-85 (in French).

18. Gillies HD. Plastic surgery of the face. London: Hodder and Stoughton, 1920:.13-15, 177-92.

19. Lindqvist C, Pihakari A, Tasanen A, Hampf G. Autogenous costochondral grafts in temporo-mandibular joint arthroplasty: a survey of 66 arthroplasties in 60 patients. $J$ Maxillofacial Surg 1986;14:143-9.

20. Hasegawa T, Yamano Y. Arthroplasty of the proximal interphalangeal joint using costal cartilage grafts. J Hand Surg [Br] 1992;17:583-5.

21. Trumble TE, Rafijah G, Gilbert $\mathbf{M}$, et al. Thumb trapeziometacarpal joint arthritis: partial trapeziectomy with ligament reconstruction and interposition costochondral allograft. J Hand Surg [Am] 2000;25:61-76.

22. Sandow MJ. Proximal scaphoid costo-osteochondral replacement arthroplasty. J Hand Surg [Br] 1998;23:201-8

23. Mcdonald G, Petrie D Un-united fracture of the scaphoid. Clin Orthop 1975;108:110-14.

24. Bouman HW, Messer E, Sennwald G. Measurement of ulnar translation and carpal height. J Hand Surg [Br] 1994;19:325-9.

25. Linscheid RL. Kinematic considerations of the wrist. Clin Orthop 1986;202:27-39.

26. Green DP, O'Brien ET. Open reduction of carpal dislocations: indications and operative techniques. J Hand Surg [Am] 1978;3:250-65. 